\title{
Corporate Education System as a Factor of Ensuring Modern Companies' Financial Stability
}

\author{
Submitted 18/08/19, 1st revision 19/09/19, 2nd revision 28/10/19, accepted 25/11/19 \\ Buryakov G.A. ${ }^{1}$, Andreeva A.V. ${ }^{2}$, Orobinskiy A.S. ${ }^{3}$, Yudin A.A. ${ }^{4}$
}

\begin{abstract}
:
Purpose: This article aims to identify the role of corporate universities opened by large holdings for their employees' effective training as a part of the company's mission implementation and ensuring business financial stability strategy.

Design/Methodology/Approach: To implement flexible project management of the companies' financial stability, a concept of corporate university development is presented on the grounds of a competency-based approach. Main emphasis of the competency-based approach is aimed at the labor functions performance and establishment of a correlation between competence and labor efficiency of employees.

Findings: Methods and techniques of corporate education are aimed at creating human capital development optimal model, ensuring the company's financial stability.

Practical Implications: The study results were tested as part of a corporate retraining program for the specialists at the "Russian Railways" company in Rostov-on-Don. Participation in corporate university programs allows employees responding quickly to market changes.

Originality/value: Main contribution of this study is to create an algorithm for transmitting the company's strategy to all management levels. The tools for key changes in the company's organizational and financial management system are formed at a corporate university.
\end{abstract}

Keywords: Corporate university, motivation, specialists' training, staff rotation, competence centers, financial stability.

JEL Codes: G20, G30.

Paper type: Research article: Corporate Education.

\footnotetext{
${ }^{1}$ Professor of the Department of "Economics and Management" at the Institute of Service and Entrepreneurship (branch campus of Don State Technical University at Shakhty), Shakhty, Russia.E-mail: gburiakov@mail.ru

${ }^{2}$ Associate Professor of department of "Economics and Finance", Office \# D507, Rostov State Transport University, certified business coach at "Corporate University of the Russian Railways", Rostov-on-Don, Russia.E-mail: alya_andreeva@mail.ru

${ }^{3}$ Associate Professor of the Department of Tax and Taxation "Voronegh State Agricultural University named after Peter the First”. Russia.E-mail: orobinski@mail.ru

${ }^{4}$ Associate Professor of department of "Economics and Finance", Office \# D507, Rostov State Transport University, Russia. E-mail: alanyudin@yandex.ru
} 


\section{Introduction}

The problem of accelerating economic growth of Russia through investment in people's knowledge and skills has been relevant for many years. Global economic growth will also slow in the coming years, especially in developing countries. In 2015, the UN adopted a new sustainable development agenda until 2030, which formulated 17 Sustainable Development Goals (SDGs) for the world community, including poverty reduction, equality and environmental protection. Through the efforts of only states and public organizations, these goals cannot be achieved, so the UN calls on businesses to focus on the SDGs in their practical activities.

The system of corporate education is connected with the need to develop competences among specialists which influences their career growth because it is associated with a level of involvement in the company's management. As a result, corporate universities opened by large Russian holdings for their employees' effective training become the part of the company's mission implementation and ensuring business financial stability strategy.

\section{Materials and Methods}

A competency-based approach started taking shape with the introduction of the "competency" concept in the scientific environment, the categorical meaning of which was disclosed in the paper of American scientist White (1959) and defined as the ability of effective interaction through a complex of personal abilities formed by training in conjunction with motivational component. Then, the competencies study got fundamental development thanks to McClelland's papers, who in 1973 defined the "competency" concept in terms of social psychology (McClelland, 1973), as a motivation for the individuals' professional, economic, and social development (McClelland, 1974). McClelland defined competencies as personality's features to display the most effective behavior, for example, interpersonal and social sensitivity, prognostic abilities, understanding the motives of other interaction participants.

American school of competency-based approach got a peak of its development in 1981-1982 thanks to the papers of Boyatzis, in which the "competency" category is connected with work efficiency (Boyatzis, 1982). The scientist defined competencies as factors based on which the work efficiency can be graded from a low to a high position. Boyatzis emphasized the importance of the competency-based approach as a tool for predicting employee's performance and achieving goals in staff development. In 1989-1993 the concepts of McClelland and Boyatzis were developed in the work of Lyle M. Spencer Jr. and Signe M. Spencer.

Based on many developed competencies models they formulated a vocabulary of competencies, where, in addition to this term definition, a scale of competencies levels was developed in accordance with the intensity of certain behavioral patterns manifestation associated with the most efficient work (Spencer and Spencer, 2005). 
As a significant result, it is worth mentioning the development by scientists of management tools as a part of the company's personnel policy relied on a competency-based approach. Since the 90s of the XXth century, vocational training relied on a competency-based approach started its development in the United States; besides the composition of competencies expanded, because of which knowledge and skills were added to the set of behavioral characteristics (Demchinkova, 2011).

The relevance of this topic was determined, first, by a shortage of skilled labor. In 1986, with the purpose to facelift the training processes, the National Body of Professional Qualifications in the United Kingdom developed a unified national system of professional skills, according to which a competency-based approach was introduced into the field of vocational education, which gave birth to a "functional" direction (The European Centre for the Development of Vocational Training, Cedefop, 2010).

This approach was characterized by the formation of professional work standards, and competencies were represented as a set of knowledge and skills required for these works that determined the required employees' behavior leading to these standards implementation at a given level (Sharifz et al., 2018).

In Germany, the competency-based approach was introduced in 1996 as part of a vocational education system. Based on the "Key competencies for Europe" symposium results held this year in Bern, a list of competencies was formulated, which were then topologized in the curriculum, being divided into the following groups: professional and technical, personalized, and social. Professional and technical competencies determine the ability to perform professional tasks, solve problems and evaluate the obtained results in terms of goals.

The Austrian branch divides competencies into four key groups: subject, cognitive, social, and personal. In Russia, the introduction of a competency-based approach is conditioned by the integration of western models started with the Sorbonne Declaration signing in 1998 and transfer of human resource management techniques into the domestic business environment. At the same time, a competency-based approach has started to be considered in educational environment as a tool for ensuring dialogue between universities and employers.

The most significant contemporary papers as a part of the competency-based approach development in education belong to Russian scientists V.I. Baidenko (2006), A.V. Khutorskoy (2002), A.K. Markova (1996), I.A. Zimnyaya (2006). A special role in the competency-based approach development in Russia is played by the validation of the "professional standard" notion by the Federal Law of December 3, 2012 in the Labor Code of the Russian Federation (Garant System, 2012), which represents a set of requirements for the employee's qualification to carry out professional activities. 


\section{Results}

\subsection{A Competency-based Approach Contributes to a Human Capital Growth}

A competency-based approach represents a combination of the company's personnel management techniques through which a person's behavior in professional activity is considered in terms of his competency's manifestation and implementation, and the focus of the approach is on efficiency of labor functions and establishment of a correlation between employee's competencies and labor efficiency (Vysochina, Svyatoho and Osmanova, 2016).

Figure 1. Content-analysis of competency definition elements ${ }^{5}$

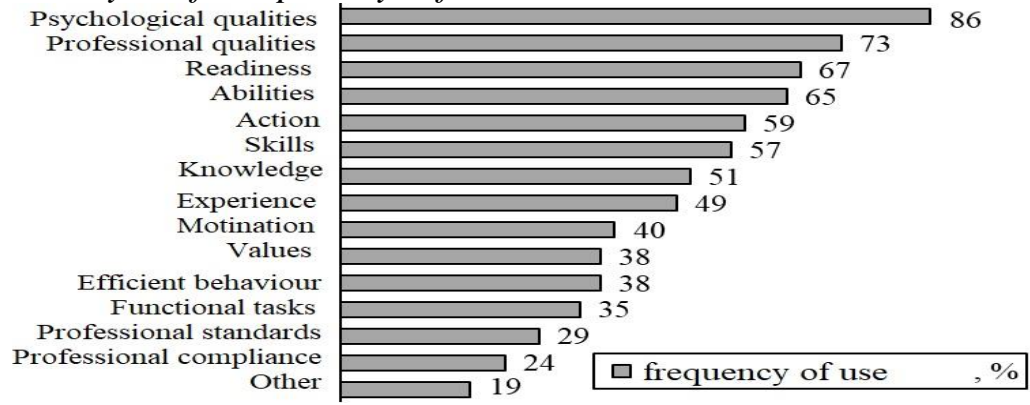

The "competency" category emergence was conditioned by the need to formalize and structure the most significant elements of human capital as a part of a single variable with the purpose of its further operationalization in view of the management measures application to it. The task of the competency operationalization conditions the need to establish a hierarchy of its constituent elements, as well as their content. The content-analysis of a significant number of competencies wording by O.L. Chulanova (Chulanova and Doroshenko, 2014) demonstrates a list of the most widespread elements defining this category (Figure 1).

Content-analysis has allowed allocating the most significant competencies, which are presented in the form of a logical hierarchy (Figure 2). Knowledge, abilities, skills and motivation together form a single competency resource that is manageable, and the presence of which serves as a basis for effective professional behavior on the employee's part. Effective behavior can be interpreted as a form of the employee's behavior, manifesting the solution of set practical tasks in accordance with established requirements, which leads to positive results.

This form of behavior characterizes the employee's competency degree, which determines the presence of the specialist's features and abilities for professional activities.

${ }^{5}$ Compiled by the authors based on the research. 
Figure 2. Logical hierarchy of core competency elements ${ }^{6}$

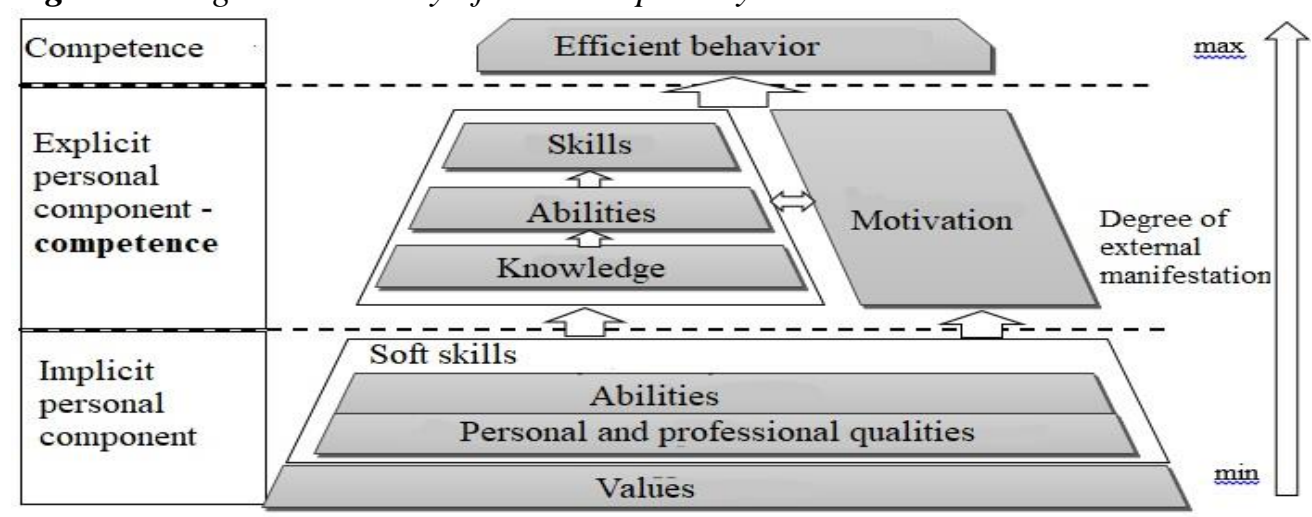

\subsection{The Importance of Human Capital Development}

The country's stability is largely determined by the role played by the professional elite in the economy development. State investment in the highly qualified specialists' production will be transformed into economic growth only in case the professionals are in demand in the labor market and have been involved in innovative companies. In this regard, the investment program in priority production should be coordinated with investment in relevant specialties. One of the factors supplementing human capital is the access of educated people to professional, administrative, social, and educational powers.

In modern economy, national wealth is gradually shifting from physical to human capital, which is becoming an increasingly important resource for economic growth. Because the income from capital depends on its value, in general, the country's welfare is determined by its human capital state. Human capital represents people's knowledge, skills and abilities with help of which they create personal, social, and economic wealth.

Main property of human capital is its lack of integrity: due to poor mobility and absence of social lifts, there is a "loss" of capital, closure of people in their territories and professional niches. Aging of the population has the worst impact on human capital, and growth of real salaries has the best one. It is difficult to predict how future professions will look in new economy, but production innovation and automation will lead to a reduction of $10-12 \%$ of existing professions in the near future. Investment in human capital, especially in the healthcare and education field, are closely related to the economic growth in modern economy. The most important investment that countries can implement is investment in human capital development. If we evaluate the economic growth dynamics over the past 25 years

${ }^{6}$ Compiled by the authors. 
and compare the indicators of the leading countries that achieved the most significant results in improving human capital with those of the countries at the rating bottom, the difference between these groups of countries is $1.4 \%$ of GDP per year (Djemaev, 2016).

These traditional methods appear inadequate in solving the problem of unemployment in the knowledge-based economy. In such an economy, it turns out to be that a man operating machine tool is becoming less and less in demand. To maintain the companies' financial stability, the use of human labor in this format is not an effective cost. Unemployment in the knowledge-based economy is a structural phenomenon. Solution of this problem lies in the educational field (new skills training and retraining) and social (redistribution of income in favor of those who are difficult to retrain) policy, and not in the monetary field. Without an increase in investment in human capital and infrastructure, it is unlikely to achieve the growth faster than $2 \%$ per year.

Due to structural problems, GDP started to slow down even before the oil prices fall. Currently, the demographic pitfall is increasing the Russian economy development risks: the number of labor force is decreasing. Without changes in the Russian labor market, education, pension and migration policies, the number of employed people aged 26-30 in 2030 will decrease by $43 \%$ compared to 2015 . Similar in scale decline will also be among 31-35-year-old employees, noted in the reports of the XIX conference of the Higher School of Economics "How to Increase Human Capital and its Contribution to Economic and Social Development." (Kuzminov, Ovcharova and Yakobson, 2018).

\subsection{Corporate Education as a Factor of Ensuring Companies' Financial Stability}

For the innovation-oriented companies' development it is important that the intellectual leadership tradition is consolidated and become sustainable. The largest Russian enterprises associate sustainable development with care for employees, social problems solvation, and environmental protection. Russian companies themselves have little incentive to invest in new technologies and sophisticated industries. Small and medium-sized businesses have insufficient factors for consolidation and capitalization. At the same time, less than one third of all employees work in Russian small and medium-sized businesses and new large companies like "Yandex". The reason is the lack of institutional conditions for people's knowledge and skills capitalization.

In this regard, the trend of creating corporate universities is developing. The concept of corporate education appeared in the 1960s at the McDonald's; with the purpose of MBA schools' graduates' adaptation, the company established its own educational center "Hamburger University". Large western corporations brought the idea of a corporate university to Russia in the early 1990s. Unlike training centers where 
individual labor skills are developed, the corporate education system ensures constant exchange of knowledge and forms a unified management culture. Participation in corporate university programs for employees to respond quickly to market changes, for which reason the companies having their own competence development centers ensure financial stability for themselves. Specialists' competencies influence their career growth, which is associated with the level of involvement in the company's management as a whole.

The main goal of a corporate university is the formation of a sustainable business development model based on the corporate responsibility system creation. In addition, to understanding the company's values and business philosophy, a corporate university allows transmitting the strategy to all the company's levels. Key changes in the company's organizational and financial management system are formed at a corporate university. In order for changes to begin in a company, they must first happen in people's heads. It is with the help of a corporate university that top management is able to transmit the understanding and essence of the changes to all the company's levels.

A corporate university creation is a long-term process, which, depending on the company's size, takes from one to three years. At the same time, according to the experts, establishment of an integrated system of internal corporate training is reasonable only for those companies where regular management is already introduced. A corporate university is required for the companies with a strict vertical management structure for the purpose to increase their mobility and get rid of rigid administrative management model disadvantages.

The tasks solved by large Russian companies to ensure financial stability are related with the problems of improving labor efficiency and rise in the specialists' competencies level. For example, the "Nornickel" company intensifies its work with universities on the graduates' vocational guidance, and corporate education accompanies its employees throughout their careers. Human capital development is an important part of the "Nornickel"'s business strategy. In 2017, the "Nornickel" launched a training program "Operational Efficiency" for top management, developed together with the "Skolkovo Business School". 55 managers attended the course, from directors and deputy directors of individual assets to the most promising shop supervisors and career chief engineers.

To attract young people, the company uses new forms of training, for example, case solving championships. A competitive environment has been created to ensure immersion in the company's activities. Based on the Siberian Federal University the "Nornickel" has created a scientific and technological center, which is for research work and a place for highly qualified specialists' training. The "Nornickel" supports a "green economy" development. In 2018 the "Nornickel" entered into an agreement with the world's largest chemical concern "BASF" to build near its Harjavalta plant 
an enterprise for the battery precursors materials production which are required for electric car batteries manufacturers.

The "Rusal Corporation" is actively promoting its own brand of environmentally compliant low-carbon aluminum ALLOW. This type of aluminum is produced using carbon-free energy sources, primarily hydropower, which allows reducing significantly greenhouse gas emissions. The environmental characteristics of this aluminum are 3 times better than the industry average; therefore, these products are in demand by the companies in the market. The company integrated all employees into one model, which allows real-time changes to be taken into account at all enterprises and, if required, to balance the risks of these changes.

The "Severstal" company, implementing a program for the labor efficiency improvement, carries out specialists' retraining aimed at growth of professional competencies and production automation. Over the past 10 years, the labor productivity has increased by 1.7 times: while from 2003 to 2006 the company produced 10.5 million tons of products per year with the help of 40,000 employees, now there are only 23,000 people. The efficiency increased from $262 \mathrm{~kg}$ per employee per year to $456 \mathrm{~kg}$; however, the company had to fire almost half of its employees.

Russian banks are also working actively to increase productivity and efficiency, for example, "Sberbank" is engaged in a program for the labor efficiency improvement based on the "lean concept", introduction of which started in 2007. The basis of this "lean concept" is a program of operational efficiency improvement by identification and elimination of hidden losses in the processes, as well as maximum involvement of all personnel in the process of continuous improvements.

The introduction of lean technologies has allowed increasing productivity by almost $50 \%$ at the end of 2018 based on technological breakthrough and increased financial performance through cost management. From 2010 to 2019 corporate competence model of the "Russian Railways" company contained a $5 \mathrm{~K}+\mathrm{L}$ competence system and corporate competence for four job levels. $5 \mathrm{~K}+\mathrm{L}$ showed how competence is related to brand values, and corporate competence described specific requirements by levels for various groups of positions in the Russian Railways. The Russian Railways Management Board approved the updated model of corporate competence in May 2019.

Herewith, of course, each specialist has his own hard skills and professional expertise. However, the soft ones, interpersonal and corporate competence are common for a railway installer, train driver, and other professions at the "Russian Railways", they are ability to work in a team, discipline and responsibility, competent organization of work, compliance with instructions and regulations, because this is the only way to ensure the safety of transportation. The corporate competence model meets those new realities in which the company operates. In 
terms of the model's structure, the number of competences in the "Russian Railways" was reduced: there were 10, and became 8 . Some competences were excluded, others were rethought and two new ones were added, being grouped into three blocks. This division has its own logic: first, the model shows what the employee should aim for in order for the company to achieve its goals - this is the first block. Then the model shows how to achieve these goals - this is the second block. In addition, the third block is key qualities that an employee needs to have in the conditions of a new economy formation.

Two new competences were added: "Development and Care for the Employees", which is a very important competence for both: the company and its managers. It was supported by most of the employees who participated in surveys inside the company. People considered as the main asset of the "Russian Railways", and top management is sure that the updated model will allow the company creating corporate environment, comfortable for the employee, more efficiently and consistently. The second new competence is "Effective Communication". Its appearance was dictated by the life itself, by the speed of occurring changes, when solving any problem requires constant interaction with colleagues, partners, and customers. Only through communication and feedback, the company's managers identify the effectiveness of managerial decisions.

\section{Discussion}

The Russian companies' approaches to sustainable development issues management have changed a lot over the past 10 years; now most of them have allocated a specialist who is engaged in this area. The main driving factor for changes in the world is a request from the investors for whom it is important to know how the company manages non-financial risks, since this reduces the risks of disruptions in work, environmental fines, accidents, etc. Financial stability means not only profit but also main stakeholders' interests' implementation - motivated personnel, local community. Measures in the corporate social responsibility field contribute to strengthening the company's image as a reliable employer and business partner.

Understanding the role of human capital for economic growth is important for public awareness. Priority of human capital means that society is in the search for a model of its development not towards the past, but towards the future. In the mid-2000s, there was a turn of the elite's attention to the human capital issues. First, it was about education and healthcare, to which the pension system was added later.

This challenge is not specifically Russian. Formation of the human potential modern effective development system is a relevant problem for all the most developed countries in modern world. Post-industrial challenges with their demographic problems led to the crisis of traditional "welfare state" and set a task to many countries of their social sphere deep transformation. In modern economy, when the population's aging process has become stable, and the demand for social services is 
steadily increasing, a radically new model of social state should be created. Creation of a new social policy model is a common problem for all developed countries in the world. Destruction of the Soviet system was a result of the industrial system crisis with its character social state institutions.

Therefore, the search for the human capital development optimal model should consider existing experience in the world. Currently, effective systems meeting modern challenges simply do not exist. Such systems should be modeled. A country that will be able to form a modern effective human capital development model will receive a powerful advantage in the post-industrial world.

\section{Conclusion}

1. A competency-based approach started taking shape with the introduction of the "competency" concept in 1959. Modern-day researchers elaborate some important aspects of the concept of a competency, such as professional skills and "soft" skills.

2. Human capital represents people's knowledge, skills and abilities with help of which they create personal, social, and economic wealth. In modern economy, national wealth is gradually shifting from physical to human capital, which is becoming an increasingly important resource for economic growth.

3. Some modern large-scale Russian companies ("Severstal", "Nornickel", "Rusal", "Rosneft", "Russian Railways", "Sberbank" etc. open corporate universities in order to train and retrain employees on their specific model of a corporate competencies and develop business development based on a corporate responsibility system' creation. Also, modern large-scale Russian companies ensure their financial stability by improving labor efficiency and rise in the specialists' competencies level.

4. The quality of professional training is determined by its components which reflect the direct peculiarity of human capital - professional competences. The priority of finding internal reserves of resource savings and maximizing of the return on one unit of incurred charges increases in the context of business conditions tightening, accompanied by decrease in the availability of external sources of financial resources for Russian companies. In these conditions the personnel composition is a factor of ensuring a company's stability.

\section{References:}

Baidenko, V.I. 2006. Revealing the University Graduates' Competencies Composition as a Required Stage in the Design of New Generation of State Educational Standard of Higher Professional Education. Moscow, Research Center for the Problems of Quality Specialists Training, 72.

Boyatzis, R.E. 1982. The Competent Manager: A Model for Effective Performance. John Wiley \& Sons.

Cedefop. 2010. The European Centre for the Development of Vocational Training. The development of national qualifications frameworks in Europe, Luxembourg, Publications Office of the European Union, available online: http://www.cedefop.europa.eu/EN/Files/6108_en.pdf. 
Chulanova, O.L. and Doroshenko, O.V. 2014. Monitoring of the Competency-based Approach Application in the Companies' Personnel Management in the Region. Kadrovik, 2, 100-105.

Demchinkova, S.A. 2011. Main Approaches to the Interpretation of the "Skills" and "Competence": Notions Abroad and their Meaningful Content. Vestnik TSPU, 13 (115), 243-244.

Djemaev, O.T. 2015. Socio-economic Importance of New Directions of Personnel Policy of Large Corporations (on the Example of the "Russian Railways"). Science and Education: Economy and Business; Law and Governance, 11(66).

Garant System. 2012. Federal Law of December 3, 2012 No. 236-FZ “On Introduction Amendments to the Labor Code of the Russian Federation and Article 1 of the Federal Law “On Technical Regulation”. Available online: http://base.garant.ru/70271730/.

Khutorskoy, A.V. 2002. Institute at the Millennium Turn (on the objectives of research to update the content of education and key competencies). Institute of General Secondary Education: to the 60th anniversary of the Russian Academy of Education and the 80th anniversary of the Institute, Moscow, IGSE RAO.

Kuzminov, Y.I., Ovcharova, L.N. and Yakobson, L.I. 2018. How to Increase Human Capital and His Contribution to Economic and Social Development. Higher School of Economics (National Research University) with the participation of the World Bank. To the XIX of April international Scientific Conference On Development Issues Economy and Society, 10-13 April, Moscow, available online: https://www.hse.ru/data/2018/04/09/ 1164472034/htm.

Markova, A.K. 1996. Psychology of Professionalism. Moscow: International Humanitarian Fund "Knowledge".

McClelland, D.C. 1973. Testing for Competence Rather Than Intelligence. American Psychologist, 28, 143.

McClelland, D.C. 1974. A Guide to Job Competency Assessment. Boston, McBer.

Sharifz, K., Mullakhmetov, N.F., Sadriev, D.R. and Akhmetshin, M.E. 2018. Corporate Culture in Management Systems. European Research Studies Journal, 21(1), 519-528.

Spencer, L.M. Jr. and Spencer, S.M. 2005. Competence at work. Moscow, HIPPO, 17-19.

Vysochina, M.V., Svyatoho, N.V., Osmanova, Z.O. 2016. A Competency-based Approach in the Company's Personnel Management. Issues and Problems of Economics and Management in the Modern World, proceedings of the III International Scientific and Practical Conference, Omsk, Areal LLC, 309-312.

White, R.W. 1959. Motivation reconsidered: the concept of competence. Psychological Review, 66.

Zimnyaya, I.A. 2006. Key competencies - a new paradigm for the result of modern education. Available online: http://www.eidos.ru/journal/2006/0505.htm. 